Portland State University

PDXScholar

\title{
Regional Trade Agreements and the Pattern of Trade: A Networks Approach
}

\author{
Rossitza Wooster \\ Portland State University, wooster@pdx.edu \\ Javier A. Reyes \\ University of Arkansas at Little Rock \\ Stuart Shirell \\ University of Arkansas at Little Rock
}

Follow this and additional works at: https://pdxscholar.library.pdx.edu/systems_science_seminar_series

Part of the International Economics Commons, and the Regional Economics Commons Let us know how access to this document benefits you.

\section{Recommended Citation}

Wooster, Rossitza; Reyes, Javier A.; and Shirell, Stuart, "Regional Trade Agreements and the Pattern of Trade: A Networks Approach" (2011). Systems Science Friday Noon Seminar Series. 62.

https://pdxscholar.library.pdx.edu/systems_science_seminar_series/62

This Book is brought to you for free and open access. It has been accepted for inclusion in Systems Science Friday Noon Seminar Series by an authorized administrator of PDXScholar. Please contact us if we can make this document more accessible: pdxscholar@pdx.edu. 


\section{色 Portland State

\section{Regional Trade Agreements and the Pattern of Trade: A Networks Approach*}

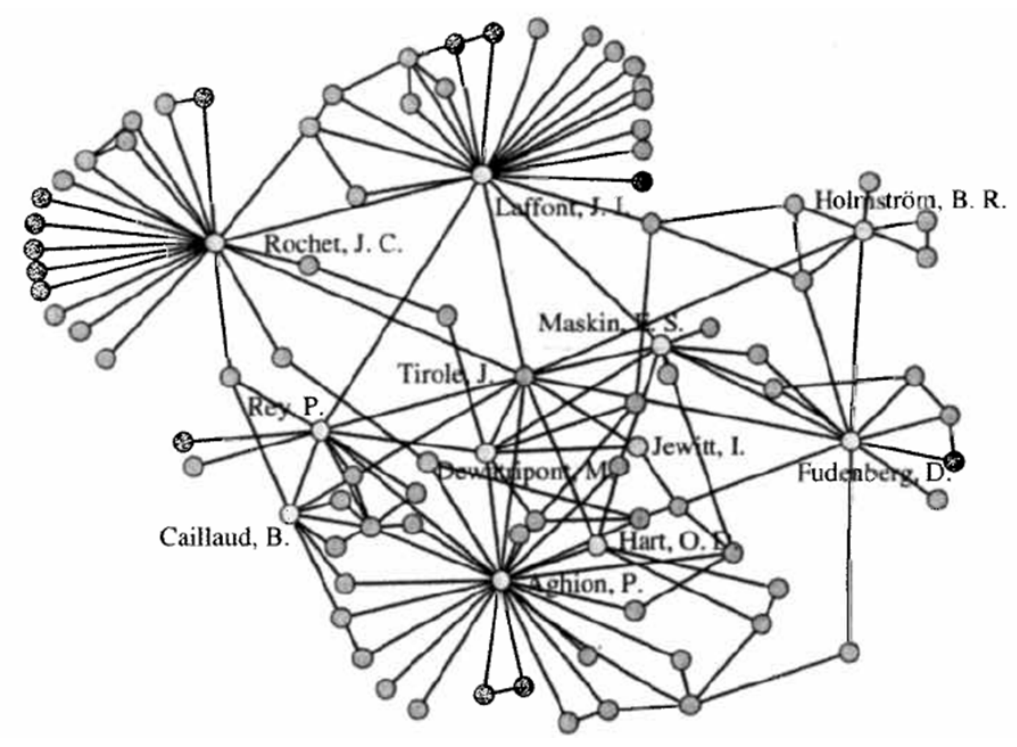

Rossitza B. Wooster (Department of Economics, PSU)

*Co-Authors: Javier A. Reyes and Stuart Shirell

(University of Arkansas)

System Science Program Seminar: April 29, 2011 


\section{色 Portland State \\ Department of Economics}

\section{Motivation}

Regional Integration vs. Multilateral Liberalization: how does trade-bloc formation affect the pattern of world trade flows?

- Old (unresolved) question $\rightarrow$ trade creation and trade diversion effects co-exist in most attempts of regional integration (Viner, 1950).

- Empirical evidence is mixed: conclusions regarding the impact of regional trade agreements are often based on gravity-type models using different time-span and different sets of Regional Trade Agreements (RTAs). Misspecification and missing dynamic effects are a concern.

- On average, trade creation effects may outweigh those associated with trade diversion but these are short-run effects. No consensus exists regarding improvements in welfare for members and non-members. 


\section{Motivation (cont.)}

Why are concerns over trade-bloc formation relevant today?

- Doha Round: economic integration through RTAs received new impetus in the wake of the collapse of multilateral negotiations in 2006 and again in 2008.

- Proliferation of RTAs (230 in force as of Dec. 2008) raises concerns over the future of multilateral trade negotiations.

$>$ Evidence suggests that much of regional integration through RTAs may be motivated by potential considerations (greater political stability and building political capital for domestic reforms).

$>$ Dec. $31^{\text {st }}$ 2011: deadline to resolve remaining issues in Doha Round negotiations (agriculture and services). 


\section{Research Objectives}

1. Evaluate the effects of RTA formation on global trade flows between 1970 and 2000 (32 RTAs considered).

2. Model the world trade system as a complex network to determine whether RTA formation has a lasting impact in shaping world trade flows.

2. Contribution:

- Complex network approach provides dynamic setting in which both short-run and long-run influences are considered.

- Networks approach is important departure from previous research which relies on the gravity model framework with treatment effects for RTAs. 


\section{Results}

The effect of regional trade integration (due to RTAs) is visible in the pattern of world trade flows. This pattern is:

1. More prominent over time;

2. Cyclical:

- Evidence of RTA formation affecting the structure of the world trade network: 1980-86 and 1990-96;

- Pattern of bilateral trade flows moves away from that which would be predicted by models based on implementation of RTAs: $1986-1990$ and 1997-2000.

Conclusions:

- Effects of RTAs most prominent in the years following implementation;

- Over time, the effects of RTAs on bilateral trade flows are diminished by longer-term influences such as overall reduction in trade costs. 


\section{蛋 Portland State \\ Department of Economics}

\section{Research Methodology}

Ideas related to methodology are organized as follows:

- Outline basic building blocks used to model the world trade system as a complex network;

- Identify the communities of trading partners in the observed network of trading relationships;

- Develop the econometric specifications used to generate fitted values of trade flows. Hypotheses are based on models predicting trade bloc formation based on geographic and economic characteristics of trading partners, and/or the implementation of RTAs;

- Community structures, obtained using the fitted values from these models, are compared against the one produced by the raw data using a Variation of Information measure. 


\section{$\int$ Portland State \\ Department of Economics}

\section{Networks: Building blocks}

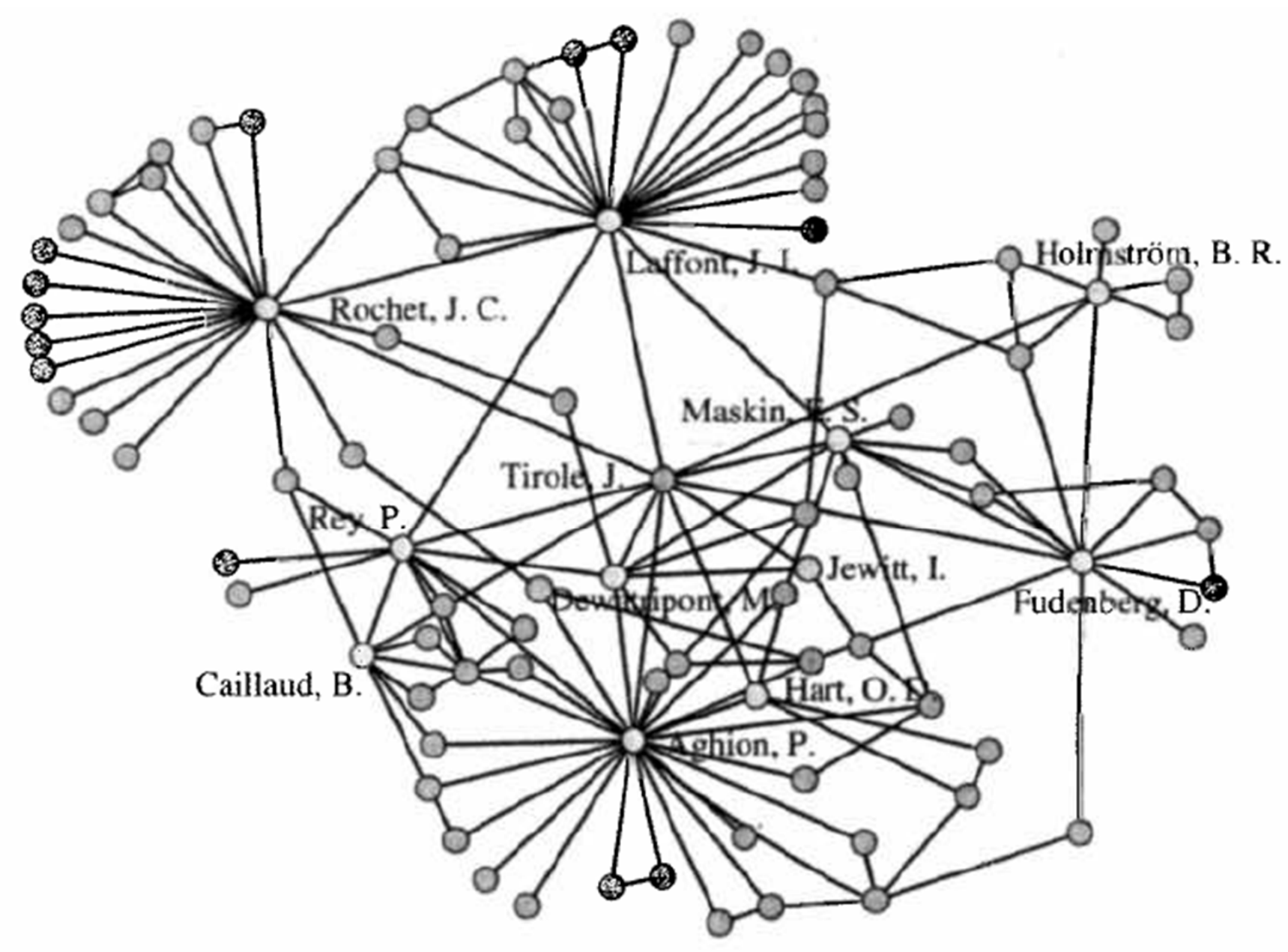

Figure 2.8. Economics coauthor network around Jean Tirole (1990s). (From Goyal, van der Leij, and Moraga 2004.) 


\section{Complex Networks: Building blocks}

We focus is on total trade flows between countries $i$ and $j$.

- Adjacency matrix: $\boldsymbol{A}=\left[\boldsymbol{a}_{i j}\right]$ such that:

$$
a_{i j}=a_{j i}=\left\{\begin{array}{l}
1 \text { if nodes } i \text { and } j \text { are linked } \\
0 \text { otherwise }
\end{array}\right.
$$

- More realistically, links here represent exports and imports between countries $i$ and $j$ in the network $\rightarrow$ links need to be both weighted and directed.

- Let $w_{i j}=$ exports of country $i$ to country $j$

$$
w_{j i}=\text { imports of country } i \text { from country } j
$$

then, redefine the interaction matrix $\boldsymbol{A}$ as:

$$
W=\left[w_{i j}\right]
$$




\section{Building blocks (cont.)}

To capture total trade flows (i.e. exports+imports), we build a symmetric matrix, $\boldsymbol{W S}=\left[\boldsymbol{w}^{s}{ }_{i j}\right]$, such that each cell represents the total interaction between countries $i$ and $j$.

Trade flows between countries are then weighted by the geometric mean of the total trade flow for the two countries for each year.

The degree (number) of all the links connected to country $i$ is:

(2) $d_{i}=\sum_{i=1}^{N} a_{i j}$

The total strength (value) of all the links connected to country $i$ is:

(3) $s_{i}=\sum_{j=1}^{N} w_{i j}^{s}$ 


\section{Communities in the World Trade Network}

Partitioning the network into communities follows Ruan and Zhang (2008):

- Let $\boldsymbol{W S}$ contain $N$ countries grouped into $K$ communities;

- Let $e_{f g}$ denote the sum of the value of all links connecting nodes in communities $f$ and $g$;

- Let $z_{f}$ be the total strength for the nodes included in community $f$, where $f \in K, g \in K$. That is, if $F$ is the subset of $N$, representing countries in community $f$, then

$$
\mathrm{z}_{f}=\sum_{i}^{F} s_{i}
$$




\section{Communities in the World Trade Network (cont.)}

Partitioning of $\boldsymbol{W} \boldsymbol{S}$ into communities can then be achieved by maximizing the modularity function

$$
Q=\sum_{k=1}^{K}\left[\frac{e_{k k}}{M}-\left(\frac{z_{k}}{M}\right)^{2}\right]
$$

where $M$ represents twice the total value of all edges in the network.

- The first term measures the fraction of total strength of all edges present inside community $k$;

- The second term denotes the expected value for such a fraction if the weighted edges within the network were rewired, keeping node degree for every country, $d_{i}$, fixed. 


\section{Null Models of Community Structures}

Assumed Classification or Proposed Model

(1)

(2) Geographical classification by Continents

(3)

(4)

(5)

(6)

(7) with Regional Trade Agreements and Fixed

Agreements

Gravity Model with Regional Trade Agreements and Fixed Effects

\section{Community Structure determined by}

Specific regional characteristics.

More general regional characteristics.

The structure defined by the regional trade agreements.

Total mass of countries represented by the product of their GDP relative to the distance between them.*

(4) + consideration the effect of RTAs

(5) + correction for endogeneity by using bilateral, country and time period fixed effects

(6) + imposing unitary income elasticities

Effects 


\section{Null Models of Community Structures}

For comparison purposes we estimate four different gravity models.

The first represents a simple gravity model: trade flows depend on the economic size of countries, the distance between them, as well as controls for common language and adjacency of countries (excluding controls for the presence of RTAs, bilateral or time fixed effects).

The second specification incorporates controls for the presence of RTAs but still excludes fixed effects.

$$
\begin{aligned}
\log X_{i j t}= & \beta_{0}+\beta_{1}\left(\log R G D P_{i t}\right)+\beta_{2}\left(\log R G D P_{j t}\right)+\beta_{3}\left(D I S T_{i j}\right)+\beta_{4}\left(A D J_{i j}\right)+ \\
& +\beta_{5}\left(L A N G_{i j}\right)+\beta_{6}\left(F T A_{i j t}\right)+\varepsilon_{i j t}
\end{aligned}
$$




\section{色 Portland State \\ Department of Economics}

\section{Null Models of Community Structures}

The final two models are based on specifications that include multilateral price variables in the analysis, these are:

$$
\begin{aligned}
\log X_{i j t}= & \beta_{0}+\beta_{1}\left(\log R G D P_{i t}\right)+\beta_{2}\left(\log R G D P_{j t}\right)+\beta_{3}\left(D I S T_{i j}\right)+\beta_{4}\left(A D J_{i j}\right)+ \\
& +\beta_{5}\left(L A N G_{i j}\right)+\beta_{6}\left(F T A_{i j t}\right)-\log P_{i t}^{1-\theta}-\log P_{j t}^{1-\theta}+\varepsilon_{i j t} \\
\log \frac{X_{i j t}}{R G D P_{i t} R G D P_{j t}}= & \beta_{0}+\beta_{3}\left(D I S T_{i j}\right)+\beta_{4}\left(A D J_{i j}\right)+\beta_{5}\left(L A N G_{i j}\right)+ \\
& +\beta_{6}\left(F T A_{i j t}\right)-\log P_{i t}^{1-\theta}-\log P_{j t}^{1-\theta}+\varepsilon_{i j t}
\end{aligned}
$$

where $X_{i j}$ and $D I S T_{i j}$ denote the level of trade and the distance between countries $i$ and $j$, respectively.

The covariates $L A N G_{i j}, A D J_{i j}$, and $F T A_{i j}$, represent dummy variables that control for common language, adjacent countries, and whether or not countries $i$ and $j$ have signed a free trade agreement, respectively. Finally, $P_{i t}$ and $P_{j t}$ denote bilateral prices for countries $i$ and $j$. 


\section{\& Portland State}

\section{Comparing Community Partitions}

We follow Meilă (2007) who develops a method of comparing community partitions based on information theory.

This approach uses an entropy-of-information measure to quantify the amount of information a particular clustering (community structure) contains as follows:

(7) $\quad H(C)=-\sum_{k \in K} P(k) \log P(k)$

where $\mathrm{P}(k)$ is given by,

(8) $\quad P(k)=\frac{\sum_{i=1}^{N} C_{i k}}{N}$

and $C_{i k}$ takes on the value of 1 if country $i$ belongs to community $k$ and zero otherwise. 


\section{Comparing Community Partitions}

The mutual information between two community partitions, $C$ and $C^{\prime}$, with $K$ and $K^{\prime}$ communities, respectively, is given by

$$
I\left(C, C^{\prime}\right)=\sum_{k \in K} \sum_{k^{\prime} \in K^{\prime}} P\left(k, k^{\prime}\right) \log \frac{P\left(k, k^{\prime}\right)}{P(k) P\left(k^{\prime}\right)}
$$

Finally, the variation of information $(V I)$ measure is defined as:

$$
V I\left(C, C^{\prime}\right)=H(C)+H\left(C^{\prime}\right)-2 I\left(C, C^{\prime}\right)
$$

Intuitively, the $V I$ measure captures a notion of the "distance" between two partitions of the same network in the entire set of network partitions. This allows us to determine the informational discrepancy between the community structure in the original data and our null communities. 


\section{Data}

- International trade flows: NBER-UN international trade database [provided and documented in Feenstra, Lipsey, Deng, Ma, and Mo (2005)];

- Distance between countries: Geographical and Distance database provided by CEPII;

- GDP Data: Economics Statistics database of the UN Statistics Division. The 32 major regional trade agreements in force in 2000: RTA Database from the World Trade Organization.

- On average, the number of bilateral observations for which we have distance and GDP data is approximately 356,000, for the $1970-2000$ sample period, including over 180 countries.

- The number of countries in the analysis, once distance and GDP data constraints are taken into consideration, is between 140 and 163, for the different years in the sample period considered. 


\section{Figure 1. Kernel Densities for Node Degree and Node Strength}

\section{令 Portland State \\ Department of Economics}

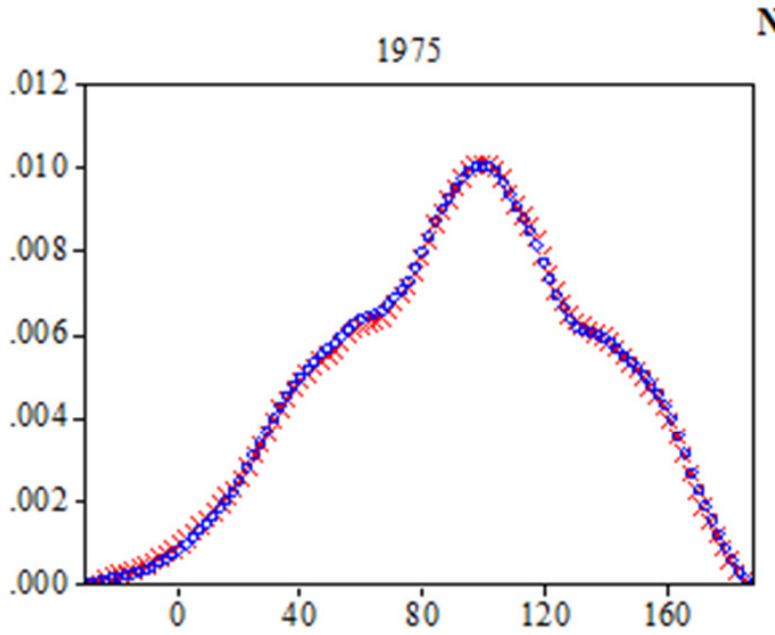

Node Degree

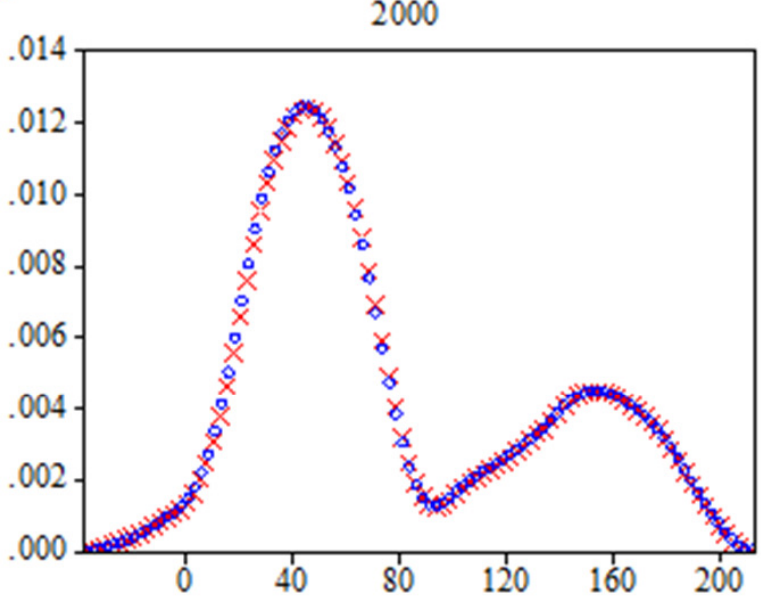

Node Strength
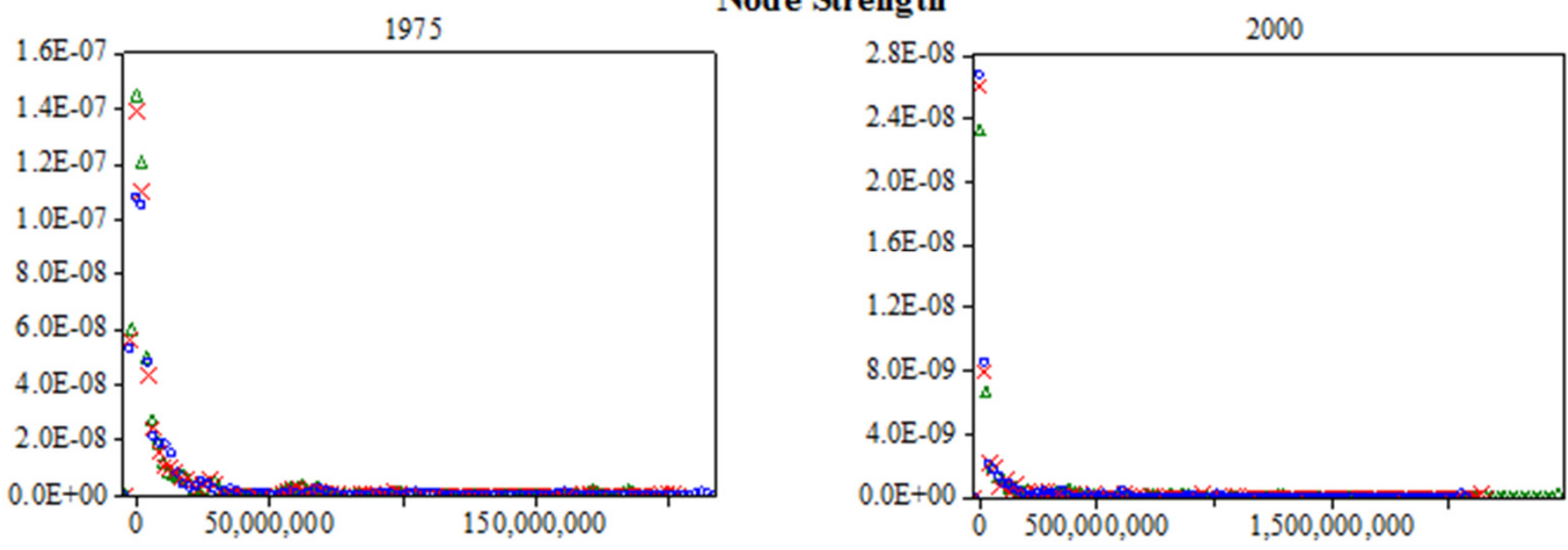

- Original Trade Network

$\times$ Fitted Trade Network from Gravity Model with Fixed Effects

$\Delta$ Fitted Trade Network from Unit Income Elasticity Gravity Model with Fixed Effects 


\section{\& Portland State}

Department of Economics

\section{Empirical Results}

Figure 2. Variation of Information (VI): comparison of the community structure derived from the original trade network and those assumed or obtained from different models.

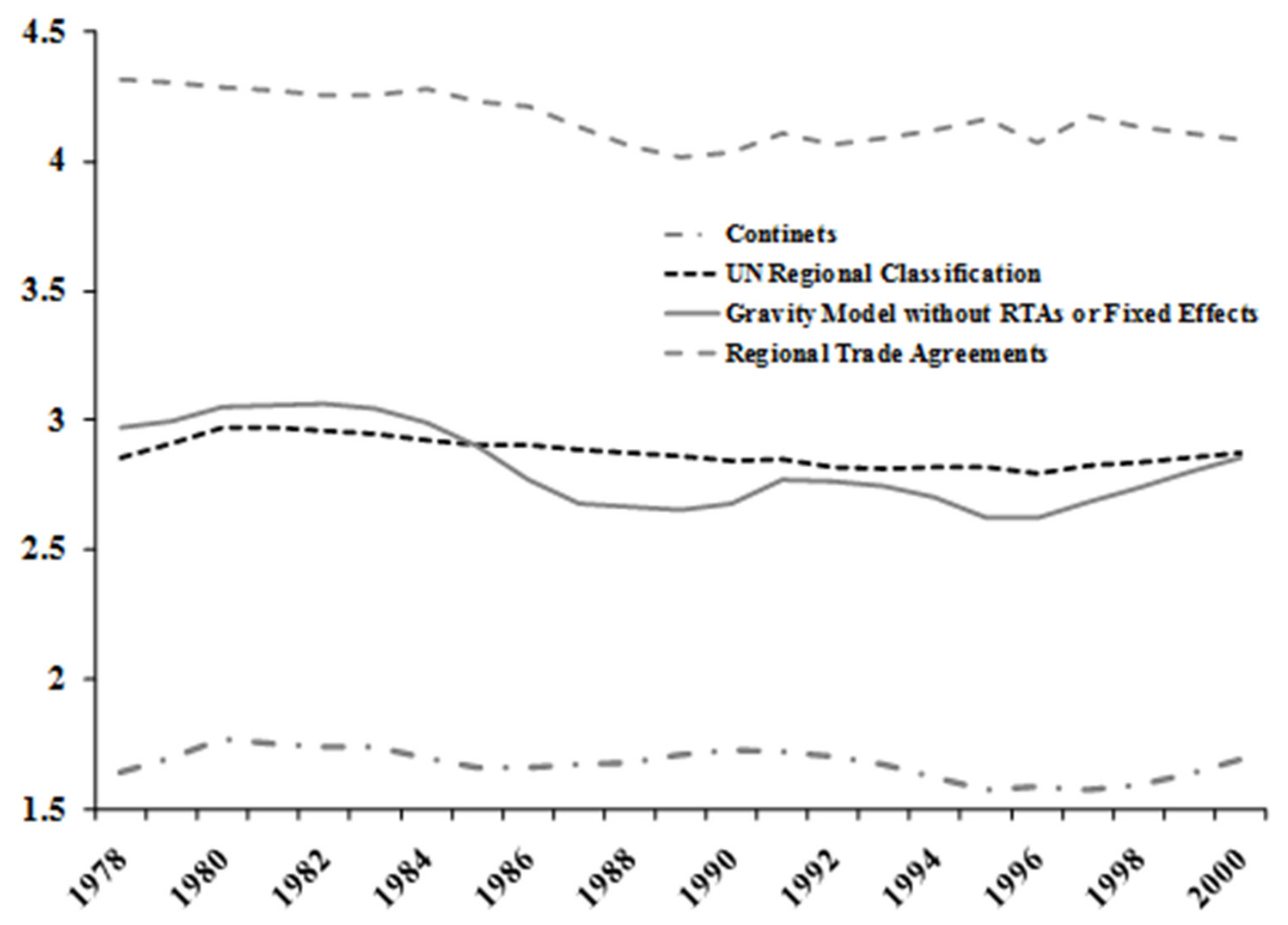




\section{\& Portland State}

Department of Economics

\section{Empirical Results}

Figure 3. Variation of Information (VI): comparison of the community structure derived from the original trade network and those obtained from different models that control for RTAs.

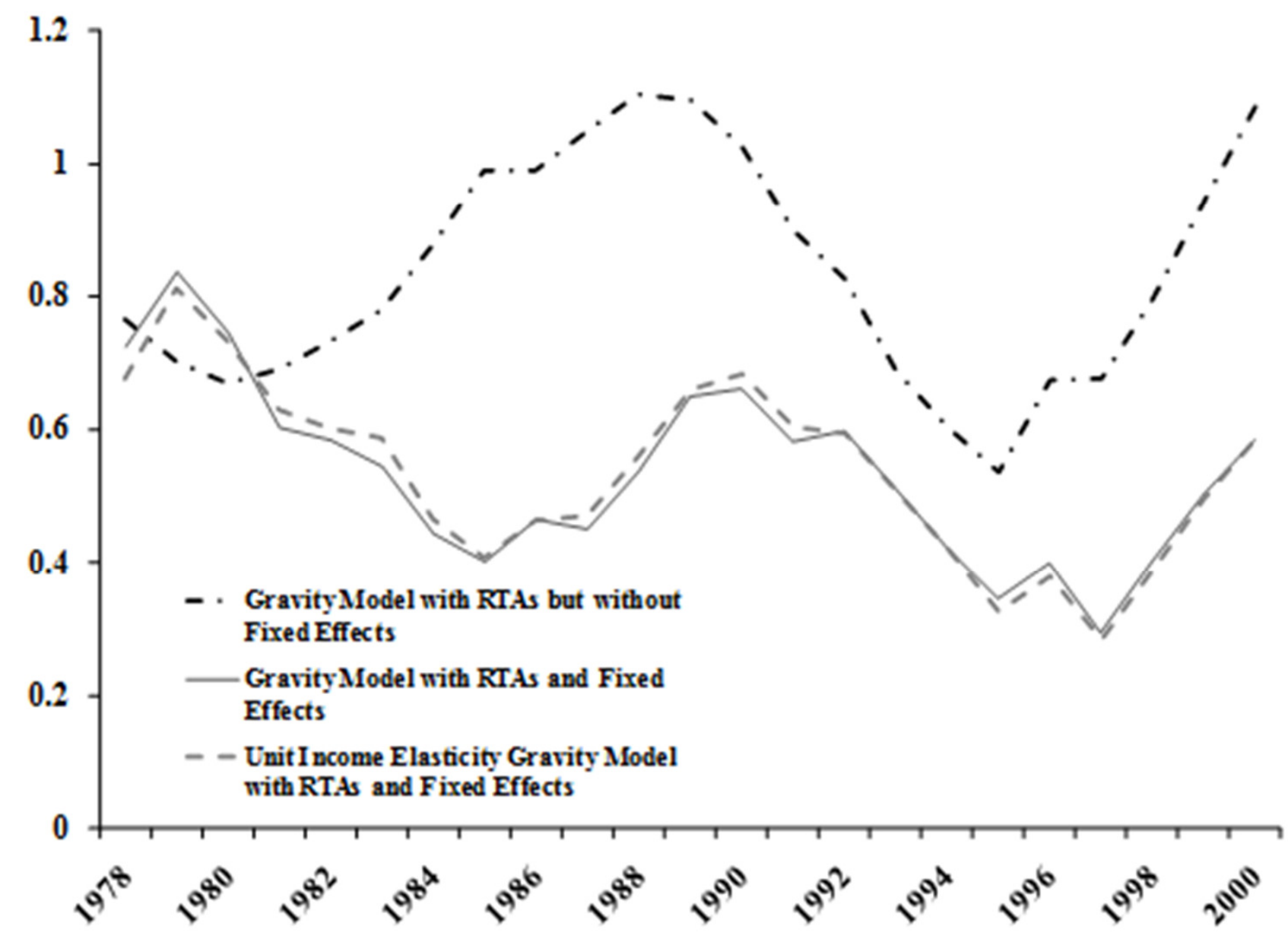




\section{\& Portland State \\ Department of Economics}

\section{Empirical Results}

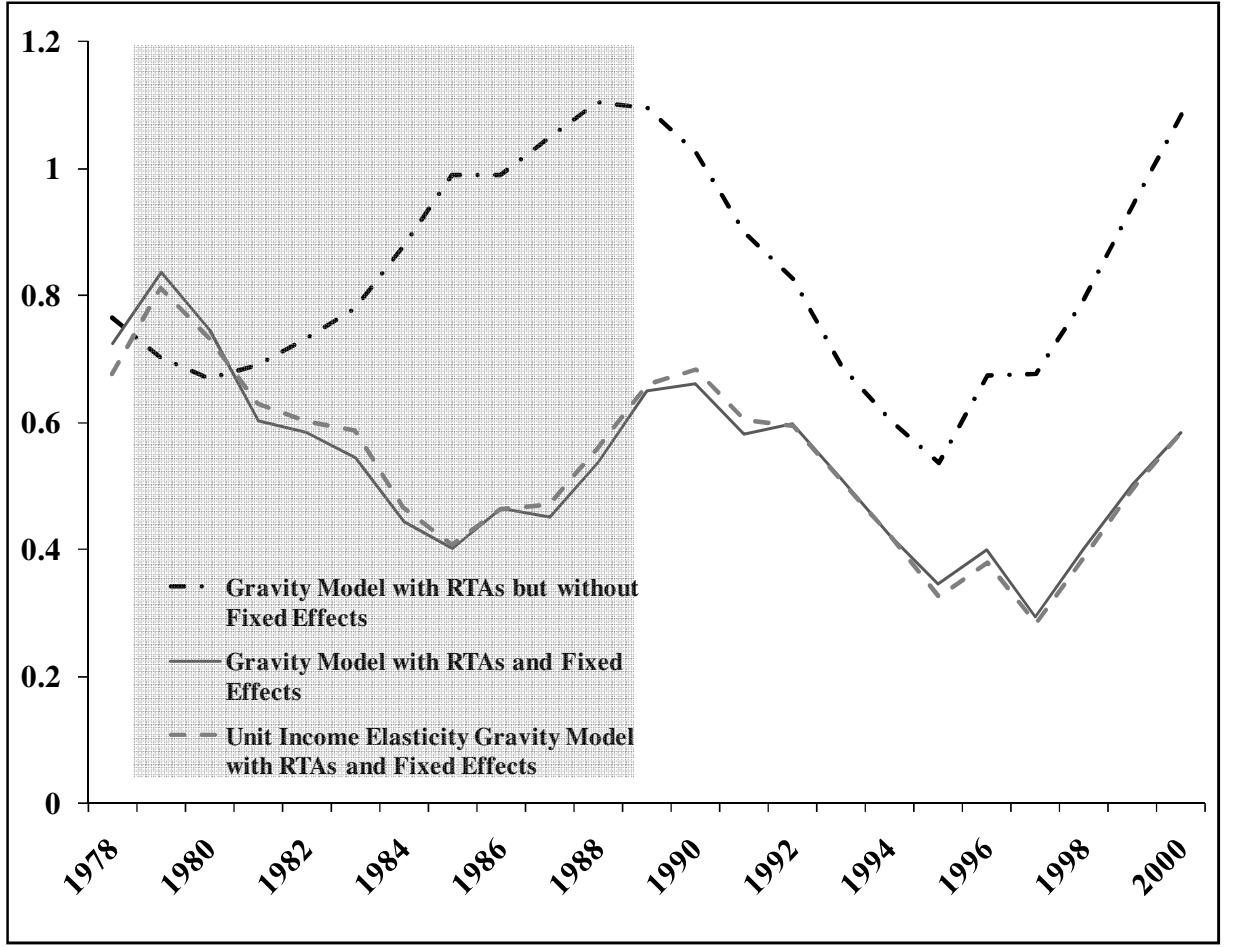

$V I$ Measures

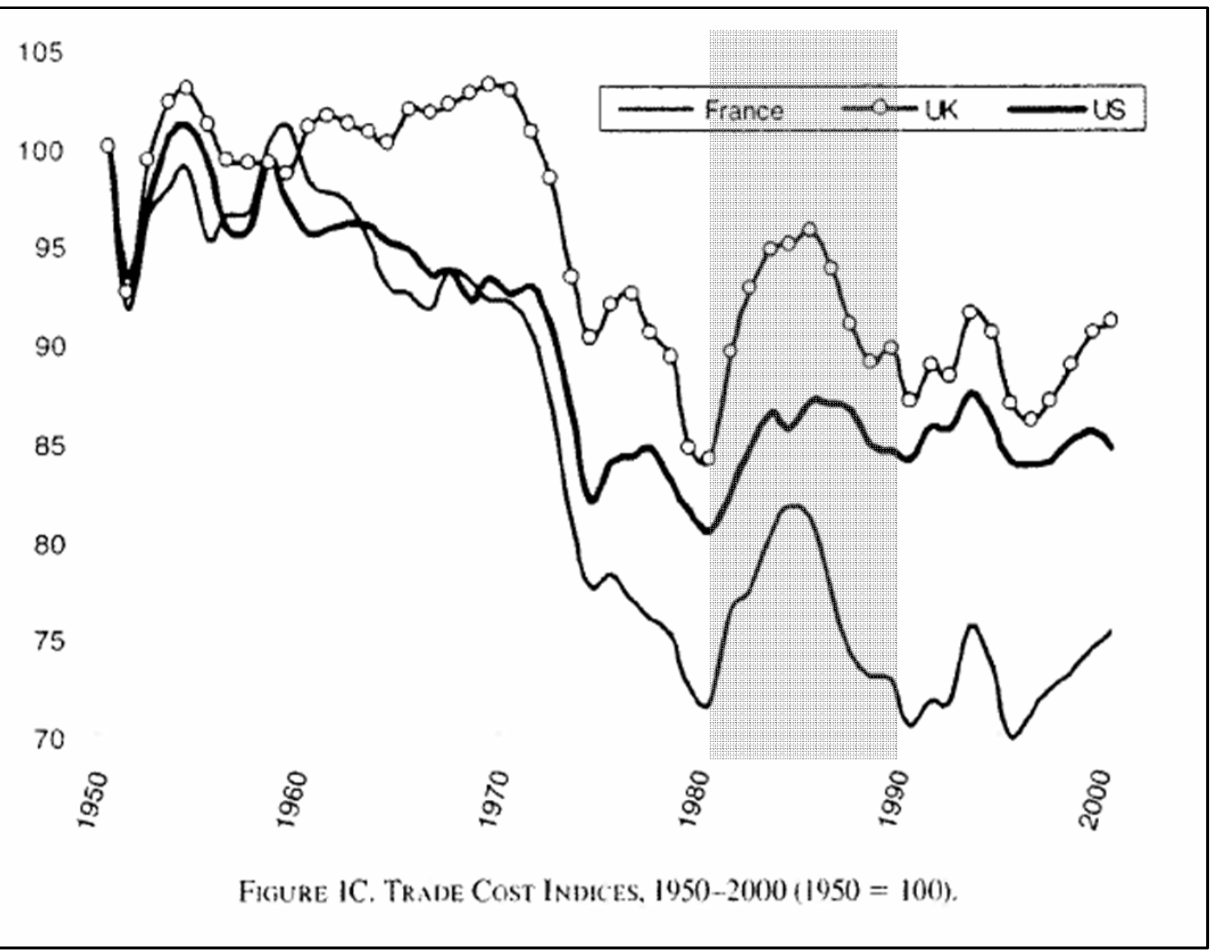

Trade Costs: Jacks et al. (2008) 


\section{Conclusions}

- We bilateral trade data between 1970 and 2000 to model world trade system as a complex network.

- We compute the community structure for every year in the sample and compared this to null community structures based on models that account for regional and geographic classifications, or the implementation of RTAs within a simple or gravity-type framework.

- Results show that RTAs appear to have an effect that strengthens over time but has cyclical components to it.

1. We document periods where bilateral trade flows in the world trade network are consistent with waves of RTAs formation. These cycles occur 1980-86 and 1990-96.

2. We also find periods in which the pattern in the world trade network community structure is not explained by RTAs formation. These occur in the periods $1986-1990$ and 1997-2000. 


\section{$\int$ Portland $\underset{U N I V E R S I T Y}{\text { State }}$ \\ Department of Economics}

\section{Conclusions}

We draw two conclusions based on previous literature, historical evidence, and the results in this paper.

- First, RTAs have had a pronounced and increasing importance in shaping the world trade network over the period 1970-2000. However, the effects of RTAs appear to be relatively short-lived and concentrated on average in the years immediately surrounding RTA formation.

- Second, cyclical differences between observed patterns of bilateral trade flows and those predicted by RTA formation suggest that overall liberalization of capital flows and reduction in trade costs may be factors that, over time, dampen the effects of RTA formation. 


\section{\& Portland State \\ Department of Economics}

\section{Future Work}

The analysis presented in this paper is only a first step in evaluating the effects of RTAs on the world trade network.

- As not all trade agreements are created equal, their differential impact on bilateral trade flows cannot be expected to be of equal magnitude or duration. The analysis of the specific characteristics of the trade agreements being proposed, signed, and implemented at different points in time offers a fruitful venue for future research.

- Such research would make it possible to assess how the number of RTAs and the size of membership impacts trade patterns relative to other determinants of trade flows. The answer to this question would be of significant use to policy makers as it would serve to further inform the choice between trade liberalization at the regional level and that through multilateral trade negotiations. 


\section{色 Portland State}

Thank You! 